\title{
Root Canal Configuration of the Maxillary Second Permanent Molars in Pakistani Subpopulation
}

\author{
Mansoor Khan ${ }^{1}$ \\ Alia Ahmed ${ }^{2}$ \\ Muhammad Qasim Javed ${ }^{3}$
}

\author{
BDS, FCPS, CHPE \\ FCPS, MHPE \\ FCPS, MSc
}

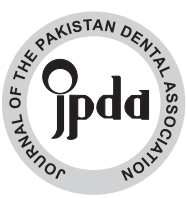

OBJECTIVE: The aim of the study is to assess the variations in the root canal configuration of maxillary second permanent molars in the Pakistani subpopulation by using different clinical aids in vivo.

METHODOLOGY: The Cross-sectional analytical study was conducted from April to October 2018 at the College of Dentistry, Riphah International University, Pakistan. The root canal configurations of Maxillary second molars were evaluated in 95 adult patients that presented to the Operative Department, after obtaining consent. After access cavity preparation the orifices were identified and cross checked using $2.5 \mathrm{x}$ magnification and different clinical tests. Data analysis was done by utilizing SPSS version 23.

RESULTS: Out of the 95 teeth 6(6.3\%) teeth had a single canal, 7(7.4\%) teeth had two canals, 58(61.1\%) teeth had three canals and $24(25.3 \%)$ teeth had four canals. Age-wise analysis of the frequency of different canals showed that prevalence of molars with three canals was significantly higher in the subjects with age between 41 and 50 years.

Conclusion: Overall, the study noted four morphological variations in the root canal configuration of Maxillary second molar teeth in Pakistani subpopulation. Hence, while executing the endodontic treatment in the maxillary second molars a thorough assessment of the root canal system should be carried out. The results of the study can guide Pakistani dentists.

KEYWORDS: Permanent Maxillary second molar, Dental Morphology, Endodontics, Pakistan

HOW TO CITE: Khan M, Ahmed A, Javed MQ. Root canal configuration of the maxillary second permanent molars in Pakistani subpopulation. J Pak Dent Assoc 2021;30(3):209-214.

DOI: https://doi.org/10.25301/JPDA.303.209

Received: 29 January 2021, Accepted: 06 April 2021

\section{INTRODUCTION}

$\mathrm{T}$ he main reason that is reported for the unfavorable outcome of an endodontic treatment is the microbial leakage to the periapical area. The leakage of microorganisms is the consequence of suboptimal instrumentation, inadequate cleaning, insufficient length and density of root canal obturation. ${ }^{1}$ Additionally, missed and untreated root canals have been highlighted as the contributory factors towards the development of periapical lesions. ${ }^{2}$ Therefore, in order to achieve a successful outcome for the endodontic procedures a thorough knowledge of the root canal system is required for adequate cleaning, shaping and obturation.

Considering the tooth morphology, one of the most variant and challenging tooth to treat is the maxillary second

1. Assistant Professor, Department of Operative Dentistry, Foundation University College of Dentistry, Islamabad, Pakistan.

2. Professor, Department of Operative Dentistry, Islamic International Dental College, Riphah Interntional University, Islamabad, Pakistan.

3. Assistant Professor, College of Dentistry, Qassim University, Buraydah, Qassim, Saudi Arabia.

Corresponding author: “Dr. Mansoor Khan” < bigbird.khan@gmail.com > molar. A few studies have investigated the morphological variations in the roots and the root canal systems of the maxillary second molars. ${ }^{3,4,5,6}$ Pecora et al examined 200 maxillary second molar teeth and found that $58 \%$ of the teeth exhibited three canals, while four canals were found in $42 \%$ of the teeth. The fourth canal was mainly found in the mesiobuccal root of these teeth.3 However, two distinct canals have also been reported in distobuccal and palatal roots. ${ }^{4,5,6}$ Libfeld and Rotstein reported that $90.6 \%$ of the second maxillary molars had three roots with three or four canals, whereas $6 \%$ of the teeth were two-rooted, $3 \%$ had a single root, and $0.4 \%$ had four roots. ${ }^{7}$

Moreover, some case reports have also been published with rare findings with respect to the number of canals and roots in the maxillary second molars. Tank documented a case of maxillary second molar having two palatal roots with two distinct canals and foramina at the apical level. ${ }^{8}$ Fava et al reported the presence of one canal and one root in both second maxillary molars of the patient ${ }^{9}$, while Alani reported four roots in the second maxillary molars of the patient bilaterally. ${ }^{10}$ Baratto-Filho et al. carried out an in vitro study of two maxillary second molars with four canals 
and two different palatal roots. ${ }^{11}$ Barbizam et al. reported a similar study of a second maxillary molar with four canals in four distinct roots. ${ }^{12}$ Benenati presented a clinical case of a second maxillary molar with two palatal roots and a groove located at the palatal side of the tooth. ${ }^{13}$

Considering, aforementioned variations in the root canal morphology of Maxillary second molar teeth. It is important that detailed visual and radiographic examination should be carried out while performing the endodontic procedure. The utilization of magnification devices like dental operating microscopes and magnifying loupes with proper lighting can significantly improve the location of canals in the clinical settings. ${ }^{14,15,16}$ The variations of the root canal systems are thought to be related to ethnicity and genetic makeup. ${ }^{17}$ There are several clinical studies on the maxillary second molars across the world, whereas, the data on the maxillary second molars is limited in Pakistan. The present study describes the use of dental loupes along with dental head light and other clinical aids like transillumination, champagne bubble test and use of 10\% India ink for locating the canals in the maxillary second molars. ${ }^{18}$ The results of the study will help the Pakistani dentists in clinical decision making with regards to pretreatment and peri-treatment planning as well as in diagnosis of endodontic retreatment cases of permanent maxillary second molars. Therefore, the objective of this study was to assess the variations in the root canal configuration of maxillary second permanent molars in the Pakistani subpopulation by using different clinical aides in vivo.

\section{METHODOLOGY}

The current cross-sectional analytical study was conducted from April to October 2018 at the Operative Dentistry Department of the Dental College of Riphah International University, Islamabad, Pakistan after obtaining the ethical apptoval from the institute (Ref. No. IIDC/1RC/2017/01/07). The sample size was calculated by using WHO calculator. Sample size was found to be 95 with confidence level of $95 \%$, relative precision of 0.10 and estimated population proportion of $58 \%{ }^{3}$ Nonprobability purposive sampling technique was used. The patients between the age of 18 and 50 years with adequate mouth opening who reported at the operative dentistry department for the endodontic treatment of maxillary second molars with irreversible pulpitis or pulp necrosis were included in the study after obtaining their consent. Patients who refused to participate in the study, presented with nonrestorable Maxillary second molars or had limited mouth opening were excluded from the study.

The patients were administered local anesthesia by infiltration technique in the buccal sulcus adjacent to the upper second molar which was to be treated followed by the rubber dam application. A standard access cavity was made using the no 4 round bur (Dentsply/Maillefer, USA) and non-end cutting tapering fissure carbide bur (EndoZ bur, Dentsply/Maillefer, USA). After deroofing the chamber completely and straightening the walls appropriately, bleeding was controlled using sodium hypochlorite wash (PD,Switzerland) and by excavating the coronal portion of the pulp with a spoon excavator (excavator 123/124, Dentsply Ash instruments, UK). After the hemostasis was achieved the chamber floor was examined with the help of $2.5 \mathrm{x}$ magnifying loupes (Gallilean loupes, Keeler, UK). The identified orifices of mesiobuccal, distobuccal and palatal canals were negotiated with size $15 \mathrm{k}$ files (SybronEndo, USA) .The presence of additional canals were then ruled out by using transillumination (TransCure, Kinetic Instruments Inc, USA), champagne bubble test and by staining the floor with $10 \%$ India ink (Pelikan,Germany). ${ }^{18}$ The additional canals thus found were then negotiated with size 10k files (SybronEndo,USA) and a radiograph was taken after placing the files in all the located canals in order to confirm the presence or absence of these canals. The findings were then recorded on a proforma stating the age and gender of the patients along with all the other information collected during the procedure.

Data analysis was done using SPSS version 23. Mean and standard deviation were described for the demographic characteristics of the participants (age and gender). Frequencies and percentages of the number of canals in second maxillary molars were also calculated. In order to control the effect modifiers the patients were stratified according to age and gender. Chi-square test was applied to see the effect of age and gender on presence of three canals. $\mathrm{P}$-value of less than 0.05 was taken as significant. The following null hypotheses were tested: (i) Age have no effect on presence of three canals (ii) Gender has no effect on presence of three canals (iii) In male patients, age has no effect on presence of three canals (iv) In female patients, age has no effect on presence of three canals.

\section{RESULTS}

Total ninety five subjects with 55(57.9\%) females and $40(42.1 \%)$ males participated in this study. The female to male ratio was $1.37: 1$. The age of the participants was between 18 years and 50 years. Overall, 37(38.9\%) patients were in age group 1(18-30 years), 28(29.4\%) patients were in age group 2(31-40 years) and $30(31.5 \%)$ were in age group 3(41-50 years). Out of the 95 teeth included in the study $6(6.3 \%)$ teeth had a single canal, $7(7.4 \%)$ teeth had 
two canals, 58(61.1\%) teeth had three canals and 24(25.3\%) teeth had four canals (Table 1).

In group 1(18-30 years), total 3 canals were found in 17 patients. In group 2 (31-40 Years) 19 patients were having 3 canals. In group 3 (41-50), 22 patients were found having 3 canals. The results showed that the chances of having 3

Table 1: Frequency and number of canals found in maxillary second molars $(\mathrm{N}=95)$

\begin{tabular}{|l|c|}
\hline Number of Canals & Frequency (\%) \\
\hline One & $6(6.3 \%)$ \\
\hline Two & $7(7.4 \%)$ \\
\hline Three & $58(61.1 \%)$ \\
\hline Four & $24(25.3 \%)$ \\
\hline Total & $95(100 \%)$ \\
\hline
\end{tabular}

Table 2: Age group comparison with the number of canals

\begin{tabular}{|l|l|l|l|}
\hline \multirow{2}{*}{ Age Group } & \multicolumn{2}{|l|}{ Three Canals } & \multirow{2}{*}{ P-Value } \\
\cline { 2 - 3 } & Yes & No & \\
\hline $18-30$ & 17 & 20 & \multirow{2}{*}{0.049} \\
\hline $31-40$ & 19 & 9 & \\
\hline $41-50$ & 22 & 8 & \\
\hline Total & 58 & 37 & \\
\hline
\end{tabular}

Table 3: Gender group comparison with number of canals

\begin{tabular}{|l|l|l|l|}
\hline \multirow{2}{*}{ Gender } & \multicolumn{2}{|l|}{ Three Canals } & \multirow{2}{*}{ P-value } \\
\cline { 2 - 3 } & Yes & No & \\
\hline Male & 29 & 11 & \multirow{2}{*}{0.051} \\
\hline Female & 29 & 26 & \\
\hline Total & 58 & 37 & \\
\hline
\end{tabular}

Table 4: Male age group comparison with the number of canals

\begin{tabular}{|l|l|l|l|}
\hline \multirow{2}{*}{ Age Group } & \multicolumn{2}{|l|}{ Three Canals } & \multirow{2}{*}{ P-Value } \\
\cline { 2 - 3 } & Yes & No & \\
\hline $18-30$ & 12 & 6 & \multirow{2}{*}{0.00} \\
\hline $31-40$ & 7 & 2 & \\
\hline $41-50$ & 10 & 3 & \\
\hline Total & 29 & 11 & \\
\hline
\end{tabular}

Table 5: Female age group comparison with the number of canals

\begin{tabular}{|l|l|l|l|}
\hline \multirow{2}{*}{ Age Group } & \multicolumn{2}{|l|}{ Three Canals } & \multirow{2}{*}{ P-Value } \\
\cline { 2 - 3 } & Yes & No & \\
\hline $18-30$ & 5 & 14 & 0.00 \\
\hline $31-40$ & 12 & 7 & \\
\hline $41-50$ & 12 & 5 & \\
\hline Total & 29 & 26 & \\
\hline
\end{tabular}

canals got significantly higher with the increasing age $(\mathrm{p}$-value $=0.049)($ Table 2$)$.

Gender-wise evaluation of teeth showed that 3 canals were found in 29 males out of 40 and 29 females out of 55 . The difference was found to be statistically insignificant $(\mathrm{p}$-value $=0.051)($ Table 3$)$.
Data was further analyzed for the presence of 3 canals in male and female patients within different age groups. Significant difference was noted in the presence of 3 canals in both male and female patients (Table 4 and Table 5).

\section{DISCUSSION}

The goal of endodontic therapy is to relieve pain and achieve healing of the periapical area. The failure to accomplish aforementioned goal results in the post treatment disease. ${ }^{2}$ The failure to eradicate the intra-radicular bacteria is the main etiological factor for the post treatment disease. These bacteria may survive within the canal due to a host of reasons including the inability of the disinfectants to reach the bacteria or missed canals during the preparation of access cavity. ${ }^{2}$ The canals which may go undetected during the access cavity preparation stage are the additional canals that occur in certain type of teeth as normal morphological variations. Apart from a thorough knowledge of the anatomy of the teeth, use of magnification and clinical adjuncts can also greatly increase our ability to identify and negotiate the canals. ${ }^{14,15,16}$ The present study was designed to make use of clinical aids during access cavity preparation of maxillary second molars in order to identify the variations in the root canal configuration of maxillary second permanent molars. The aids included the magnifying dental loupes, staining of the pulp chamber floor, use of trans-illumination and the champagne bubble test. ${ }^{18}$

The prevalence of one and four canals in the current research were comparable with the findings of study conducted by Shafqat et al on the Pakistani population. ${ }^{19}$ The prevalence of second maxillary molar teeth with one and two canals was significantly higher in Pakistani population as compared to the Brazilian population (0\%).3 Conversely, Pecora and colleagues reported significantly higher percentage of second maxillary molars (42\%) with 4 canals in Brazilian cohort. ${ }^{3}$ The percentages of four canals in Pakistani population were found to be $25.3 \%$ in current study and $21.25 \%$ as reported by Shafqat et al. ${ }^{19}$ Accordingly, Peikoff et al noted $22.7 \%$ of the maxillary second molars with four canals in the American population while using radiographic method to assess the number of canals. ${ }^{20}$ Olczak reported $70 \%$ maxillary second molars with three canals while $23.2 \%$ teeth had four canals in polish population. The frequency of one canal was $1 \%$ and two canals was $3.9 \%$ in the same study. ${ }^{21}$ Interestingly, although observed using $\mathrm{CBCT}$ which is a very accurate method for detecting root morphology, the findings of Olczak et al closely match the result of the present study. According to Naseri et al $31 \%$ teeth had 3 canals while 4 canals were found in $67.5 \%$ teeth. $1.2 \%$ teeth had 5 canals while none of the teeth had single canal or two canals. ${ }^{22}$ The 
variation in the findings might be attributed to the difference in the ethnicities that can affect the morphology of the root canals and the number of root canals. ${ }^{23}$ Another factor can be the different investigative methods used by the researchers. ${ }^{3,20,24}$

All the teeth with four canals in the current study had fourth canal in the Mesio-buccal (MB) root. The findings were in line with several previous researches where fourth canal was found as an additional canal in the MB root of the maxillary second molar. ${ }^{3,5,7,15,16,20}$ Pecora et al investigated 200 maxillary second molars by utilizing the clearing technique and found that $42 \%$ of the teeth with four canals had the fourth canal exclusively located in their MB roots. ${ }^{3}$ Likewise, Peikoff and colleagues, while investigating 520 Maxillary second molars reported that fourth canal was located in the MB root of all the teeth with four canals $(22.7 \%) .{ }^{20}$

The prevalence of three canals in present study was about $61 \%$. Whereas the study by Shafqat et al on Pakistani population has reported the prevalence of $50 \% .{ }^{19}$ The authors did not find any further study on second maxillary molars in Pakistani population. The findings of current study were in line with the results reported in American (56.9\%) and Brazilian (58\%) populations. Cross tabulation of the age and the frequency of different canals showed that the highest number of three canaled molars was present in group 3(41-50 years) that is 22 teeth which is consistent with the trend observed in other in vivo ${ }^{24,25}$ and in vitro studies. ${ }^{3,26,27}$ This suggest that with age calcification of the mb 2 canals leads to its obliteration and decreases the number of negotiable canals to 3 . The lowest number of three canaled molars was present in the group 1(18- 30 years) that is 17 teeth. The incidence of four canaled molars however, showed a reverse trend. The highest incidence of these teeth was found in group 1(18-30years) that is 18 teeth. The lowest incidence of these teeth was found in group 3(41-50 years), that is only 1 tooth. The findings obtained via correlation between age and number of canals were in line with the findings of the previous studies which suggest that in younger individuals the mb2 canal is not completely calcified and may be negotiable clinically even under $2.5 \mathrm{x}$ magnification. ${ }^{3,20}$

The comparative findings of various studies also show great discrepancy in the incidence of the second mesio-buccal canal. The frequency of its occurrence ranges from $18.6 \%$ to $93 \% .{ }^{28}$ Apart from this the presence of lesser number of four canaled molars in groups with individuals of older ages may also be due to the difference in the methodology applied in detecting the number of canals with sensitivity of $2.5 \mathrm{x}$ loupes being significantly less than in vivo methods like examination under dental operating microscope. Several studies have shown that the use of higher magnification methods such as the use of dental operating microscopes significantly improve the ability of the operator to locate and negotiate additional canals such as the MB2 canal. ${ }^{14,15,16}$ Das et al reported that their ability to localize the second MB canal increased from $36 \%$ to $68 \%$ in the subjects with age between 36 and 45 years, when selective dentine removal using ultrasonic devices was done under the dental operating microscope. ${ }^{29}$ This demonstrates that in older individuals, even with increased chance of calcification of canals, the use of magnification and appropriate instruments may significantly increase the success

of localization and negotiation of MB2 canal.

Several in vitro methods have been used to evaluate root canal morphology and the number of root canals. These include clearing of tooth and various ink injections into the canal $^{22,30}$ pulp floor inspection with scanning electron microscope ${ }^{31}$ and examination of teeth with the three dimensional (3D) radiographic methods like CBCT and micro $\mathrm{CT} .{ }^{32}$ The $3 \mathrm{D}$ radiographic methods have reported a higher incidence of a second mesiobuccal canal as compared to other methodologies. ${ }^{27,28,32}$ The $3 \mathrm{D}$ reconstruction of the root canal system, as provided by this technique, greatly improves the ability of the operator to locate canals which would otherwise be missed in 2 dimensional radiographic techniques. ${ }^{27}$ The downside to $\mathrm{CBCT}$ is the large radiation dose when used in vivo and lower resolution as compared to the micro CT. This makes micro CT a more attractive tool in finding prevalence of canals. Micro CT is however an in vitro tool only and cannot be employed in vivo to detect the number of canals and root morphology preoperatively, unlike CBCT. ${ }^{33,24}$

The limitations of the current study include the limited sample size, single center study and the use Dental loupes with 2.5x magnification for canal location. Being a single centered study a discreet approach should be employed while generalizing the findings of the study. The study also did not take into examine the number of roots of maxillary second molars in the studied population. It is recommended that in future multicenter study with a large sample size should be conducted by utilizing the three dimensional radiographic methods. The findings of such study will be applicable to whole Pakistani population.

\section{CONCLUSION}

In conclusion the chances of having three canals in both male and female got high with the increase in age and there was no significant difference in prevalence between male and female subjects. The study also highlighted the 
importance of magnification and other clinical aids in the detection of the canals. Therefore, while preparing the access cavity in the maxillary second molars the pulp floor should be carefully examined under magnification, supplemented with clinical aids, to detect all present canals.

\section{CONFLICT OF INTEREST}

None to declare

\section{REFERENCES}

1. Mahmood S, Yahya AA, Saad AH, Hussain KA. Reasons for root canal treatment in Students and Interns clinics in College of Dentistry, King Saud University, Saudi Arabia. J Pak Dent Assoc 2003;12:336.

2. Siqueira JR JF, Rôças IN. Clinical Implications and Microbiology of Bacterial Persistence after Treatment Procedures. J Endodon 2009;34:1291-301.

https://doi.org/10.1016/j.joen.2008.07.028

3. Pécora JD, Woelfel JB, Soussa-Neto MD, Issa EP. Morphologic study of the maxillary molars. Part II: Internal anatomy. Brazil Dent J 1992;3:53-7.

4. Hülsmann M. A Maxillary First Molar with Two Distobuccal Root Canals. Journal of Endodontics 1997;23:707-08. https://doi.org/10.1016/S0099-2399(97)80407-4

5. Fahid A, Taintor JF. Maxillary second molar with three buccal roots. J Endod 1988;14:181-83.

https://doi.org/10.1016/S0099-2399(88)80261-9

6. Stone LH, Stroner WF. Maxillary Molars Demonstrating More than One Palatal Root. Oral Surg Oral Med Oral Pathol Oral Radiol Endod 1981;51:649-52.

https://doi.org/10.1016/S0030-4220(81)80017-5

7. Libfeld H, Rotstein I. Incidence of four-rooted maxillary second molars: literature review and radiographic survey of 1,200 teeth. J Endod 1989;15:129-31.

https://doi.org/10.1016/S0099-2399(89)80134-7

8. Aljabreen TM. Maxillary second molar with two palatal roots: A case report. J Pak Dent Assoc 2005 ;14:49-51.

9. Fava L, Weinfeld I, Fabri F, Pais C. Four second molars with single roots and single canals in the same patient. Int Endod J 2000;33: 138-42.

https://doi.org/10.1046/j.1365-2591.2000.00272.x

10. Alani AH. Endodtontic treatment of bilaterally occurring 4-rooted maxillary second molars: case report. J Can Dent Assoc 2003;69: 733-35.

11. Barrato-Filho F, Fariniuk LF, Ferriera EL, Pecora JD, Cruz-Filho
AM, Soussa-Neto MD. Clinical and macroscopic study of maxillary molars with two palatal roots. Int Endodontics J 2009;35:796-801. https://doi.org/10.1046/j.1365-2591.2002.00559.x

12. Barbizam JV, Ribeiro RG, Tanomaru Filho M. Unusual Anatomy of Permanent Maxillary Molars. JEndodontics 2004;30:668-71. https://doi.org/10.1097/01.DON.0000121618.45515.5A

13. Benenati FW. Maxillary Second Molar with Two Palatal Canals And Palatogingival Groove. Journal of Endodontics 1985;11:308-10 https://doi.org/10.1016/S0099-2399(85)80163-1

14. Schwarze T, Baethge C, Stecher T, Geurtsen W. Identification of second canals in the mesiobuccal root of maxillary first and second molars using magnifying loupes or an operating microscope. Aust Endod J 2002;28:57-60.

https://doi.org/10.1111/j.1747-4477.2002.tb00379.x

15. Buhrley LJ, Barrows MJ, BeGole EA, Wenckus CS. Effect of magnification on locating the MB2 canal in maxillary molars. J Endod 2002;28:324-27.

https://doi.org/10.1097/00004770-200204000-00016

16. Liang RZ, Wu YN, Hu M. Diagnostic test study of dental operating microscope used for locating the second mesiobuccal canal orifice in maxillary first molars. West China J Stomatolog 2007;25:125-8.

17. Song JS, Choi HJ, Jung IY, Jung HS, Kim SO. The prevalence and morphologic classification of distolingual roots in the mandibular molars in a Korean population. J Endod 2010;36:653-7. https://doi.org/10.1016/j.joen.2009.10.007

18. Hargreaves KM, Berman LH. Cohen's pathways of the pulp expert consult. Elsevier Health Sciences; 2015.

19. Shafqat A, Munir B, Sajid M. Maxillary Second Molar; Variations in Root Canal Morphology in Maxillary Second Molar in Patients undergoing Root Canal Treatment. Prof Med J. 2018;25: 981-86.

https://doi.org/10.29309/TPMJ/18.4570

20. Peikoff MD, Christie WH, Fogel HM. The maxillary second molar: variations in the number of roots and canals. Int Endod J 1996;29: 365-69.

https://doi.org/10.1111/j.1365-2591.1996.tb01399.x

21. Olczak, K., Pawlicka, H. The morphology of maxillary first and second molars analyzed by cone-beam computed tomography in a polish population. BMC Med Imaging 17, 68 (2017). https://doi.org/10.1186/s12880-017-0243-3

22. Naseri M, Ali Mozayeni M, Safi Y, Heidarnia M, Akbarzadeh Baghban A, Norouzi N. Root Canal Morphology of Maxillary Second Molars according to Age and Gender in a Selected Iranian Population: A Cone-Beam Computed Tomography Evaluation. Iran Endod J. 2018;13:373-380.

23. Sert S, Bayirli GS. Evaluation of the root canal configurations of the mandibular and maxillary permanent teeth by gender in the Turkish 
Khan M/ Ahmed A/ Javed MQ

population. J Endod 2004;30:391-98. https://doi.org/10.1097/00004770-200406000-00004

24. Al Shalabi RM, Omer OE, Glennon J, Jennings M, Claffey NM. Root canal anatomy of maxillary first and second permanent molars. Int Endodontic J 2000;33:405-14.

https://doi.org/10.1046/j.1365-2591.2000.00221.x

25. Nosonowitz DM, Brenner MR. The major canals of the mesiobuccal root of the maxillary 1st and 2nd molars.NYJ Dent 1973;43:12-5

26. Pineda F, Kuttler Y. Mesiodistal and buccolingual roentgenographic investigation of 7,275 root canals. Oral Surgery, Oral Medicine, Oral Pathology 1972;33:101-10.

https://doi.org/10.1016/0030-4220(72)90214-9

27. Pomeranz HH, Fishelberg G. The secondary mesiobuccal canal of maxillary molars. J Am Dent Assoc 1974;88:119-24 https://doi.org/10.14219/jada.archive.1974.0045

28. Ghasemi N, Rahimi S, Shahi S, Samiei M, Frough Reyhani M, Ranjkesh B. A Review on Root Anatomy and Canal Configuration of the Maxillary Second Molars. Iran Endod J 2017;12:1-9.

29. Das S, Warhadpande MM, Redij SA, Jibhkate NG, Sabir H. Frequency of second mesiobuccal canal in permanent maxillary first molars using the operating microscope and selective dentin removal: A clinical study. Contemp Clin Dent 2015;6:74-78.

https://doi.org/10.4103/0976-237X.149296
Root canal configuration of the maxillary second permanent molars in Pakistani subpopulation

30. Khan M, Khan RM, Javed MQ, Ahmed A. Root Canal Configuration of the Mesio-buccal Root of Maxillary First Permanent Molars in Local Population. JIIMC 2018; 13: 210-14.

31. Gilles J, Reader A. An SEM investigation of the mesiolingual canal in human maxillary first and second molars. Oral Surg Oral Med Oral Pathol 1990;70:638- 43.

https://doi.org/10.1016/0030-4220(90)90415-O

32. Grande NM, Plotino G, Gambarini G, et al. Present and future in the use of micro-CT scanner 3D analysis for the study of dental and root canal morphology. Ann Ist Super Sanita 2012;48:26-34.

33. Zhang R, Yang H, Yu X, Wang H, Hu T, Dummer PM. Use of CBCT to identify the morphology of maxillary permanent molar teeth in a Chinese subpopulation. International Endodontic J 2011;44:16269.

https://doi.org/10.1111/j.1365-2591.2010.01826.x

34. Wolf TG, Paqué F, Woop AC, Willershausen B, Briseño-Marroquín B. Root canal morphology and configuration of 123 maxillary second molars by means of micro-CT. Int J Oral Sci. 2017;9:33-37. https://doi.org/10.1038/ijos.2016.53 